\title{
Beneficial Effects of Pentanema vestitum Linn. Whole Plant on the Glucose and Other Biochemical Parameters of Alloxan Induced Diabetic Rabbits
}

\author{
Ikram Ilahi, ${ }^{1}$ Ali Asghar, ${ }^{2}$ Shujat Ali, ${ }^{2}$ Murad Khan, ${ }^{3}$ and Nasrullah Khan ${ }^{2}$ \\ ${ }^{1}$ Department of Zoology, University of Malakand, Chakdara, Dir Lower 25000, Khyber Pakhtunkhwa, Pakistan \\ ${ }^{2}$ Department of Botany, University of Malakand, Chakdara, Dir Lower 25000, Khyber Pakhtunkhwa, Pakistan \\ ${ }^{3}$ Department of Biotechnology, University of Malakand, Chakdara, Dir Lower 25000, Khyber Pakhtunkhwa, Pakistan
}

Correspondence should be addressed to Nasrullah Khan, nasrullahdushkheli@yahoo.com

Received 9 August 2012; Accepted 12 September 2012

Academic Editors: F. J. Miranda, T. B. Vree, and S.-N. Wu

Copyright ( $) 2012$ Ikram Ilahi et al. This is an open access article distributed under the Creative Commons Attribution License, which permits unrestricted use, distribution, and reproduction in any medium, provided the original work is properly cited.

\begin{abstract}
The residents of Lower Dir and Malakand agency, Khyber Pakhtunkhwa, Pakistan, use the dry powder of whole plant of Pentanema vestitum for the treatment of asthma and diabetes. No documented reports are available about the therapeutic action of Pentanema vestitum. The present study was aimed to explore the antihyperglycemic effect of $70 \%$ methanol extract of Pentanema vestitum whole plant in glucose-induced nondiabetic hyperglycemic and alloxan-induced diabetic rabbits. During this study, the effects of plant extract on the serum lipid profile, GPT, ALP, bilirubin and creatinine of diabetic rabbits were also studied. The extract of Pentanema vestitum whole plant exhibited significant $(P<0.05)$ antihyperglycemic activity in glucose-induced hyperglycemic rabbits. Treatment of alloxan-induced diabetic rabbits with extract significantly $(P<0.05)$ reduced the elevated levels of serum glucose, GPT, ALP, bilirubin and creatinine. During the study of lipid profile, the extract proved to be antihyperlipidemic and HDL boosting in diabetic rabbit models. From the finding of the present research, it was concluded that the $70 \%$ methanol extract of Pentanema vestitum whole plant has beneficial effects on serum levels of glucose, lipid profile, GPT, ALP, bilirubin, and creatinine of diabetic rabbits.
\end{abstract}

\section{Introduction}

Diabetes mellitus is a group of metabolic diseases characterized by hyperglycemia resulting from defects in insulin secretion, insulin action, or both. The type of diabetes that occurs due to the loss of insulin producing beta cells of the islets of Langerhans in the pancreas is called type 1 or insulin-dependent diabetes mellitus (IDDM) and the type of diabetes which is due to insulin resistance or reduced insulin sensitivity is called type 2 or non-insulin-dependent diabetes mellitus (NIDDM).

The diabetic patients manifest the classic signs and symptoms of chronic hyperglycemia (polydipsia, polyuria, blurred vision, headaches, and rapid weight loss), sometimes accompanied by nausea and vomiting [1]. Hyperglycemia is associated with an alteration in lipid parameters which leads to cardiovascular complications [2]. The incidence of diabetes is increasing worldwide. In Pakistan the prevalence of diabetes is high ranging from 7.6 to $11 \%[3,4]$. More than 230 million people globally are affected by the disease [5].

Diabetes mellitus is treated by different allopathic medicines. Insulin-dependent diabetes mellitus is treated by subcutaneous administration of exogenous insulin. Non-insulin-dependent diabetes is treated by oral hypoglycemic drugs. The two major groups of oral hypoglycemic drugs are Sulphonylureas and biguanides. Sulphonylureas act by stimulating insulin release from beta cells and also by promoting its action through other mechanism. The common Sulphonylureas are Tolbutamide, Tolazamide, Glibenclamide, Glipizide, and Glimepiride. Biguanides exert their action by decreasing gluconeogenesis and increasing the peripheral glucose consumption. The marketed Biguanides is Metfor$\min [6]$.

Management of diabetes is a huge burden. Currently available antidiabetic pharmacological agents have several complications which stimulated the researchers to explore 
novel antidiabetic agents with different mechanism of action [7]. It is hypothesized that the ultimate therapy for type I and type II diabetes lies in the herbal approach [5]. There are many online published reports on the usefulness of medicinal plants in the treatment of diabetes.

Pakistan is rich in medicinal plants [8]. Some of them have been reported for their antidiabetic actions. These include Adhatoda vasica, Ficus benghalensis, Psidium guajava, Momordica charantia, Cajanus cajan, Vigna mungo, Allium cepa, Zizyphus jujuba, Dodonaea viscosa, Ocimum sanctum, Momordica charantia, Trigonella foenum-graecum, Solanum nigrum, Vigna sinensis, and Withania somnifera [9].

Many medicinal plants are used in folkloric medicines for the management of diabetes, at individual or community levels in various parts of Pakistan. Several of these plants have not been screened or reported for their antidiabetic property. The plant Pentanema vestitum Linn. is one of the medicinal plants found in some parts of Malakand division, khyber Pakhtunkhwa, Pakistan. It belongs to the family Asteraceae and genus Pentanema. It grows wild at 400-1500 m height from sea level. The Pentanema vestitum has tap root system; up to some extent, the branched root system is also present. The stem is erect, branched and herbaceous in nature; the leaf is exstipulate, serrate entire and oblong. The inflorescence is capitulating or capitula and radially arranged in the form of loose corymbs [10]. The residence in some parts of Malakand division, use the dry powder of whole plant of Pentanema vestitum for the treatment of asthma and diabetes. The plant Tridax procumbens that belong to the family Asteracea to which Pentanema vestitum belong has been reported for antihyperglycemic activity $[11,12]$. The antidiabetic property of medicinal plants is attributed to their possession of phytochemical ingredients that is, tannins, saponins, glycosides, flavonoids, and phenols [13-16]. Therefore during the present work, initially Pentanema vestitum extract was subjected to phytochemical screening for investigating the presence of anti-hyperglycemic ingredients and in the next steps the extract was orally administered to glucose induced nondiabetic hyperglycemic rabbits and alloxan-induced diabetic rabbits. The objective of the study was to confirm the antidiabetic activity of the plant Pentanema vestitum and also to assess its beneficial effects on other biochemical parameters of alloxan-induced diabetic rabbit models.

\section{Materials and Methods}

2.1. Plant Material. The whole plant of Pentanema vestitum Linn. was collected from the campus of University of Malakand, Khyber Pakhtunkhwa, Pakistan. The plant was identified by Mr. Mehboob ur Rahman, Assistant professor, Department of Botany, Government Postgraduate Jahanzeb College Swat Khyber Pakhtunkhwa, Pakistan.

2.2. Preparation of Crude Extract. The plant was cleaned, shade dried, and coarsely ground. The powder material in the amount of 600 grams was soaked in $5000 \mathrm{~mL}$ of $70 \%$ methanol for 3 days with occasional shaking. The soaked materials was filtered through muslin cloth. This procedure was repeated for three times, and the combine filtrate was then evaporated on a rotary evaporator Heidolph Laborota 4000 efficient (Germany) under reduced pressure and obtained a thick solution. This extract in thick solution form was transferred to a beaker and placed in a well-ventilated room for three days for evaporating the remaining solvent, and finally a thick paste of crude extract of grayish color was obtained, yielding approximately 78 grams $(13 \% \mathrm{w} / \mathrm{w})$.

2.3. Preliminary Phytochemical Screening. A preliminary phytochemical screening of 70\% methanol extract of Pentanema vestitum whole plant was carried out by using standard procedures [17].

2.4. Animal Used. Fifty-six male rabbits of Oryctolagus cuniculus species weighing 1200-1500 grams and 4-6 months of age were purchased from local market. They were housed in one of wide chambers of Bio Park at University of Malakand, Khyber Pakhtunkhwa, Pakistan. The rabbits were fed on green grasses and allowed tape water ad libitum. They were acclimatized for 30 days before starting experiment.

2.5. Acute Toxicity Studies. The acute toxicity test of the extract was performed according to the OECD guidelines no. 420. A total of 20 male rabbits were used for this test. The rabbits were divided into four groups, 5 rabbits in each group. The four groups of rabbits were orally administered with various doses of the extract ranging from 1000 to $2500 \mathrm{mg} / \mathrm{Kg}$ body weight. The animals were monitored for two weeks for mortality and behavioral, neurological, and autonomic responses. No death occurred and also no abnormalities were detected in behavioral, neurological and autonomic responses till the end of second week. The extract was found to be safe up to the dose of $2500 \mathrm{mg} / \mathrm{Kg}$ body weight. In the present study the extract dose of $600 \mathrm{mg} / \mathrm{Kg}$ body weight was chosen during the study of glucose-induced hyperglycemic rabbits and the extract dose of $100 \mathrm{mg} / \mathrm{Kg}$ body weight during the study of alloxan-induced diabetic rabbits.

2.6. Experimental Design. The research work was divided into two phases. During the first phase, the anti-hyperglycemic property of plant extract was tested in glucoseinduced nondiabetic hyperglycemic rabbits. The second phase involved the study of effects of plant extract on the serum levels of glucose, GPT, ALP, bilirubin and creatinine of alloxan-induced diabetic rabbits.

2.7. Details of the First Phase. A total of 15 rabbits were used during this phase. The rabbits were divided into control, standard and extract-treated groups. Pretreatment ( 0 hour) blood glucose levels of all the rabbits were measured after a 17-hours fast. Then, the control group was orally administered with $2 \%$ DMSO solution ( $3 \mathrm{~mL} / \mathrm{kg}$ body weight), standard group with glibenclamide $(0.2 \mathrm{mg} / \mathrm{kg}$ body weight $)$ dissolved in $3 \mathrm{~mL}$ of $2 \%$ DMS solution, and extract-treated group with Pentanema vestitum extract $(600 \mathrm{mg} / \mathrm{kg}$ body weight) in $3 \mathrm{~mL}$ of $2 \%$ DMSO solution. After 30 minutes of 
drug and extract administration, all the rabbits were orally administered with glucose at the dose of $2 \mathrm{~g} / \mathrm{kg}$ body weight. Blood glucose levels were measured through an electronic glucometer (Accu check Advantage $\Pi$, Roche Diagnostics, Germany) with a single drop of blood from marginal vein of rabbit ear after 1/2, 1,2, and 3 hour, of glucose load.

2.8. Details of the Second Phase. During the second phase of experiment a total of 21 alloxan-induced diabetic rabbits were divided into three groups, namely, diabetic control, standard and extract groups (7 rabbits each). The rabbits of control group received only $2 \%$ DMSO in amount of $2 \mathrm{~mL} / \mathrm{kg}$ body weight per oral, standard group received glibenclamide at a dose of $0.2 \mathrm{mg} / \mathrm{kg}$ body weight per oral per day in $2 \mathrm{~mL}$ of $2 \%$ DMSO solution and extract group received Pentanema vestitum extract at a dose of $100 \mathrm{mg} / \mathrm{kg}$ body weight/oral/day in $2 \mathrm{~mL}$ of $2 \%$ DMSO solution. The duration of the treatment was 28 days.

2.9. Induction of Diabetes. Before induction of diabetes baseline serum glucose, cholesterol, triglyceride, LDL, HDL, GPT, ALP, bilirubin, and creatinine estimation was done. Then a $3 \mathrm{~mL}$ solution of $100 \mathrm{mg}$ alloxan monohydrate for per kilogram body weight of each rabbit was prepared in $0.9 \%$ saline. Three-milliliter solution of $100 \mathrm{mg}$ alloxan for per $\mathrm{kg}$ body weight was injected into the peritoneal cavity of each rabbit for 3 consecutive days. Before the injection of alloxan, the rabbits were given 12 hour fasting. Each day, each rabbit was orally given $2 \mathrm{~mL}$ solution of $500 \mathrm{mg}$ glucose prepared in distilled water. After 24 hours of each alloxan injection, the blood glucose was regularly estimated through an electronic glucometer (Accu check Advantage $\Pi$, Roche Diagnostics, Germany) with a single drop of blood from marginal vein of rabbit ear. The rabbits with glucose level above $200 \mathrm{mg} / \mathrm{dL}$ were considered diabetic and included in the experiment.

2.10. Dosing Procedure. A $400 \mathrm{~mL}$ solution of 20 grams of $70 \%$ methanol crude extract of Pentanema vestitum was prepared in 2\% DMSO solution. Each $\mathrm{mL}$ of the solution was containing $50 \mathrm{mg}$ of extract. Each rabbit of extract-treated group was orally administered with extract solution in amount of $2 \mathrm{~mL} / \mathrm{kg}$ body weight per day. For standard group each day $2 \mathrm{mg}$ of glibenclamide was dissolved in $20 \mathrm{~mL}$ distilled water. Each $\mathrm{mL}$ of the solution was containing $0.1 \mathrm{mg}$ of glibenclamide. Each rabbit of standard group was orally receiving $2 \mathrm{~mL}$ of glibenclamide solution which was containing $0.2 \mathrm{mg}$ of glibenclamide for $1 \mathrm{~kg}$ body weight per day. For all oral administrations, esophageal catheter was used.

2.11. Collection of Blood and Isolation of Serum. After 28 days of treatment $3 \mathrm{~mL}$ of blood was collected from lateral saphenous vein of each rabbit using syringe with $23 \mathrm{GX1}^{\prime \prime}$ gauge needle. Blood obtained from the lateral saphenous vein of each rabbit into a falcon tube was allowed to clot. Serum samples were obtained by centrifuging the clotted blood samples at $4500 \mathrm{rpm}$ for 5 minutes, using Eppendorf Centrifuge $5702 \mathrm{R}$.
2.12. Chemical/Kits and Equipment Used during Experiment. Alloxan monohydrate (Applichem, Germany), glucose kit (Biomega, Germany), cholesterol (Lab Test, Brazil), triglyceride (Biomega Laboratories, Holzheim, Germany), LDL (Thermo Scientific, USA), HDL kit (Thermo Scientific, USA), GPT kit (FAR srl Italy), ALP kit (Dia sys International, Germany), bilirubin liquicolor (Human, Germany), and creatinine kit (Chromatest, Spain). For the estimation of all the serum parameters, UV spectrophotometer (1700 Shimadzu Japan) was used.

2.13. Statistical Analysis. Results are presented as means \pm standard deviation/standard error of means. The data of the first phase of experiments was subjected to Duncan, test, and the data of second phase of experiments was analyzed by Dunnett, Test of Post Hoc Multiple comparison in One Way ANOVA. For these analysis, computers software SPSS 16.0 was used.

\section{Results}

3.1. Preliminary Phytochemical Studies and Acute Toxicity Studies. The Preliminary Phytochemical studies of $70 \%$ methanol extract of Pentanema vestitum whole plant revealed the presence of tannins, saponins, glycosides, flavonoids and phenols. The acute toxicity studies showed that the extract is safe up to the dose of $2500 \mathrm{mg} / \mathrm{kg}$ body weight in rabbits.

3.2. Results of the First Phase of Experiments. During the first phase of the present research, the anti-hyperglycemic effect of $70 \%$ methanol extracts of Pentenema vestitum whole plant was studied in glucose-induced nondiabetic hyperglycemic rabbits (Figure 1). During this study, at zero hour, there was no significant difference in the blood glucose levels of all groups $(P>0.05)$. After $1 / 2$ hour of glucose load, there occurred extensive increase in the glucose levels of all the groups, however the mean glucose levels of the glibenclamide $(305.2 \pm 9.1 \mathrm{mg} / \mathrm{dL})$ and the Pentenema vestitum extracttreated groups $(294.2 \pm 16.09 \mathrm{mg} / \mathrm{dL})$ were non-significantly $(P>0.05)$ lower than the glucose-loaded control group $(318.5 \pm 18.12 \mathrm{mg} / \mathrm{dL})$. After the 2 nd hour of glucose load the level of glucose declined in all the groups in response to time. The mean glucose level of the glibenclamide (149 \pm $11.4 \mathrm{mg} / \mathrm{dL})$ and the extract-treated group $(126.2 \pm 6.2 \mathrm{mg} /$ $\mathrm{dL})$ was lower than that of the hyperglycemic control group $(182.5 \pm 1.7 \mathrm{mg} / \mathrm{dL})$, and this time the difference was significant $(P>0.05)$. The plant extract and the drug glibenclamide were statistically homogeneous in antihyperglycemic activity $(P>0.05)$. After 3 rd hour of glucose load the drug and the extract were still showing glucose-lowering activity. The blood glucose level of the drug $(93 \pm 11.95 \mathrm{mg} / \mathrm{dL})$ and the extract-treated group $(114.2 \pm 12.91)$ was significantly lower than the hyperglycemic control group $(135 \pm 6.21 \mathrm{mg} / \mathrm{dL})$ $(P>0.05)$. This time also the drug and the extract showed similar anti hyperglycemic effect $(P>0.05)$.

3.3. Results of the 2nd Phase of Experiments. During the second phase of experiment the diabetic rabbits showed high 


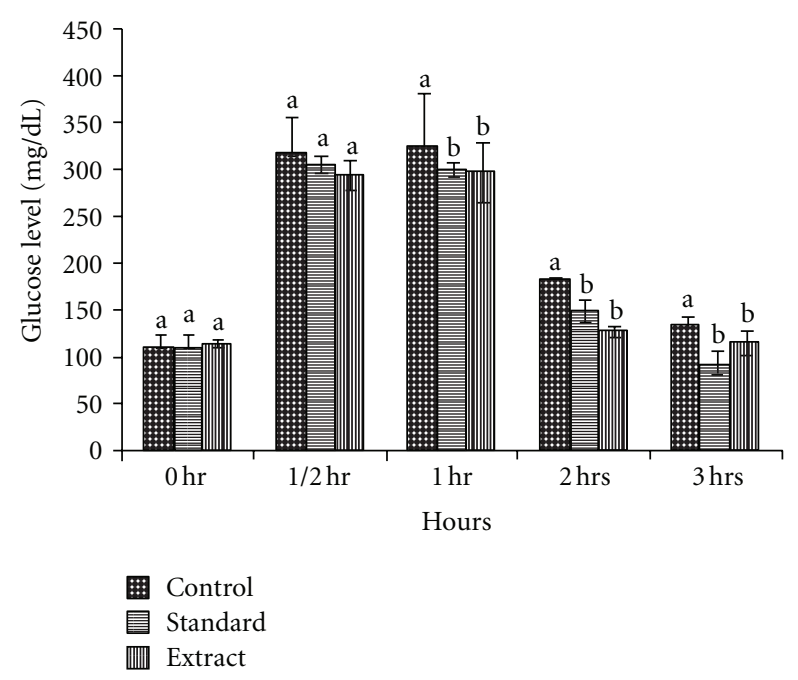

Figure 1: The effect of $70 \%$ methanol extract of Pentanema vestitum whole plant on the blood glucose level of glucose-induced nondiabetic hyperglycemic rabbits. Values are means and standard deviation of 5 replicates. Mean sharing a letter in common are not significantly different at $P<0.05$. Means sharing no letter in common are significantly different at $P<0.05$.

level of serum glucose, cholesterol, triglyceride, LDL, GPT, ALP, bilirubin, creatinine and low level of HDL (Table 1). The effects of $70 \%$ methanol extract of Pentenema vestitum on these parameters have been shown in Table 2. During the assessment of serum glucose, the Pentenema vestitum extract and the standard reference drug glibenclamide caused $18.95 \%$ and $13.43 \%$ reduction, respectively. The difference from diabetic control was significant $(P<0.05)$.

During the study of lipid profile, there occurred significant reduction in the serum levels of cholesterol, triglycerides and low density lipoprotein (LDL) both in the extract- and drug-treated groups as compared to diabetic control $(P<$ $0.05)$. The observed effects with extract were more pronounced than the drug glibenclamide. Extract caused 58.5\% reduction in cholesterol, $46.14 \%$ in TG and $57.90 \%$ reduction in LDL. Whereas glibenclamide caused $34.54 \%$ reduction in cholesterol, $26.07 \%$ in TG and $26.02 \%$ reduction in LDL. The Pentanema vestitum extract and the reference drug glibenclamide showed a different effect on serum high density lipoproteins (HDL) than on other lipids. The serum HDL levels were significantly elevated both in extract (90\%) and glibenclamide $(60.99 \%)$ treated groups as compared to diabetic control group $(P<0.05)$.

During the study of serum levels of GPT, ALP, bilirubin and creatinine the standard drug glibenclamide caused $29.05 \%$ reduction in serum GPT, $24.12 \%$ in ALP, $25.32 \%$ in bilirubin and $34.61 \%$ reduction in creatinine. The effects of Pentanema vestitum extract on these parameters were more pronounced which caused $55.67 \%$ reduction in serum GPT, $61.28 \%$ in ALP, $61.28 \%$ in bilirubin and $40.38 \%$ reduction in creatinine. The mean levels of these parameters in the animals of extract- and drug-treated group were significantly lower as compared to the diabetic control group $(P<0.05)$.
TABLE 1: Serum parameters of rabbits before and after induction of diabetes $(N=7)$.

\begin{tabular}{lcc}
\hline Parameters & Before diabetes & $\begin{array}{c}\text { After diabetes } \\
\text { diabetic control) }\end{array}$ \\
\hline Glucose $(\mathrm{mg} / \mathrm{dL})$ & $103.57 \pm 5.1$ & $\begin{array}{c}250.1 \pm 7.8 \\
(+141.47 \%)\end{array}$ \\
Cholesterol (mg/dL) & $15.3 \pm 4.6$ & $\begin{array}{c}46.6 \pm 6.3 \\
(+204.57 \%)\end{array}$ \\
Triglyceride (mg/dL) & $33.9 \pm 3.1$ & $\begin{array}{c}81.7 \pm 10.9 \\
(+141 \%)\end{array}$ \\
LDL (mg/dL) & $10.9 \pm 2.4$ & $39.2 \pm 7.5$ \\
& & $(+259.6 \%)$ \\
HDL $(\mathrm{mg} / \mathrm{dL})$ & $27.0 \pm 3.2$ & $14.1 \pm 5.6$ \\
& $11.7 \pm 3.5$ & $(-47.77 \%)$ \\
GPT (U/L) & & $(+5.71 \pm 4.29$ \\
& $9 \pm 1.5$ & $51.14 \pm 3.64 \%)$ \\
ALP (U/L) & & $(+468.2 \%)$ \\
Bilirubin (mg/dL) & $0.5 \pm 0.1$ & $2.23 \pm 0.14$ \\
& & $(+364 \%)$ \\
Creatinine (mg/dL) & $0.45 \pm 0.01$ & $2.08 \pm 0.9$ \\
& & $(+362.2 \%)$ \\
\hline
\end{tabular}

Values are means and standard error of means (SEM) of 7 replicates. Values in parentheses indicate percent increase $(+)$ or decrease $(-)$ in parameters of diabetic animals from normal baseline values.

\section{Discussion}

The preliminary phytochemical studies of $70 \%$ methanol extract of Pentanema vestitum whole plant revealed the presence of tannins, saponins, glycosides, flavonoids and phenols. These ingredients have been reported for their antihyperglycemic activity $[13,14]$.

In the present study, during the first phase of experiments, 70\% methanol extract of Pentanema vestitum whole plant showed anti-hyperglycemic property in glucose-induced nondiabetic hyperglycemic rabbits. During this study, initially glucose level remarkably elevated in all groups but after two hours of glucose administration there occurred a decline in glucose level of all groups. Pancreas is the primary organ involved in sensing the organism's dietary and energetic states via glucose concentration in the blood and in response to elevated blood glucose, insulin is secreted [18]. In conditions of high blood glucose level, oxidative metabolism is increased in pancreatic $\beta$-cells which results into increased ATP production in mitochondria [19-21]. The increase in intracellular ATP closes the ATP-sensitive $\mathrm{K}^{+}$ channels $\left(K_{\mathrm{ATP}}\right)$, decreasing the hyperpolarizing outward $\mathrm{K}^{+}$ flux. This results in depolarization of the plasma membrane and influx of extracellular $\mathrm{Ca}^{2+}$ through the voltage-gated $\mathrm{Ca}^{2+}$ channels. The increase in intracellular $\mathrm{Ca}^{2+}$, activates protein motors and kinases, which then mediate exocytosis of insulin-containing vesicles which lead to increased insulin and decreased blood glucose levels [22].

In the extract- and drug-treated groups of rabbits the glucose level was found significantly lower as compared to the control group, representing the supportive action of extract and drug glibenclamide in glucose utilization. The 
TABLE 2: Biochemical parameters of alloxan-induced diabetic rabbits after 28 days treatment with drug and $P$. vestitum extract $(N=7)$.

\begin{tabular}{|c|c|c|c|}
\hline Parameters & Diabetic control & Std & Pv ext \\
\hline Glucose (mg/dL) & $250.1 \pm 7.8$ & $\begin{array}{c}216.5 \pm 4.7^{*} \\
(-13.43 \%)\end{array}$ & $\begin{array}{c}202.7 \pm 7.7^{*} \\
(-18.95 \%)\end{array}$ \\
\hline Cholesterol (mg/dL) & $46.6 \pm 6.3$ & $\begin{array}{c}30.5 \pm 7.3^{*} \\
(-34.5 \%)\end{array}$ & $\begin{array}{c}19.3 \pm 7.3^{*} \\
(-58.5 \%)\end{array}$ \\
\hline Triglyceride (mg/dL) & $81.7 \pm 10.9$ & $\begin{array}{c}60.4 \pm 8.2^{*} \\
(-26.07 \%)\end{array}$ & $\begin{array}{l}44.0 \pm 6.5^{*} \\
(-46.14 \%)\end{array}$ \\
\hline $\mathrm{LDL}(\mathrm{mg} / \mathrm{dL})$ & $39.2 \pm 7.5$ & $\begin{array}{c}29.0 \pm 3.8^{*} \\
(-26.02 \%)\end{array}$ & $\begin{array}{l}16.5 \pm 5.8^{*} \\
(-57.90 \%)\end{array}$ \\
\hline $\mathrm{HDL}(\mathrm{mg} / \mathrm{dL})$ & $14.1 \pm 5.6$ & $\begin{array}{r}22.7 \pm 5.4^{*} \\
(+60.99 \%)\end{array}$ & $\begin{array}{l}26.8 \pm 5.6^{*} \\
(-90.07 \%)\end{array}$ \\
\hline GPT (U/L) & $76.71 \pm 4.29$ & $\begin{array}{c}54.42 \pm 2.09^{*} \\
\quad(-29.05 \%)\end{array}$ & $\begin{array}{c}34.0 \pm 2.7^{*} \\
(-55.67 \%)\end{array}$ \\
\hline $\operatorname{ALP}(\mathrm{U} / \mathrm{L})$ & $51.14 \pm 3.26$ & $\begin{array}{l}38.8 \pm 3.4^{*} \\
(-24.12 \%)\end{array}$ & $\begin{array}{l}19.8 \pm 3.2^{*} \\
(-61.28 \%)\end{array}$ \\
\hline Bilirubin (mg/dL) & $2.23 \pm 0.14$ & $\begin{array}{c}1.74 \pm 0.09^{*} \\
(-25.32 \%)\end{array}$ & $\begin{array}{c}1.03 \pm 0.15^{*} \\
(-55.7 \%)\end{array}$ \\
\hline Creatinine (mg/dL) & $2.08 \pm 0.9$ & $\begin{array}{c}1.36 \pm 0.6^{*} \\
(-34.61 \%)\end{array}$ & $\begin{array}{c}1.24 \pm 0.5^{*} \\
(-40.38 \%)\end{array}$ \\
\hline
\end{tabular}

Std: standard glibenclamide group and Pv ext: $P$. vestitum extract group. Values are means and standard error of means of 7 replicates. ${ }^{*}$ The mean difference is significant at $P<0.05$ level. Values in parentheses indicate percent changes from the diabetic control group.

anti-hyperglycemic effect of glibenclamide during oral glucose tolerance test has been attributed to enhance activity of beta cells of pancreas resulting in secretion of large amount of insulin [23]. Mechanism behind the anti-hyperglycemic activity of the extract may involve insulin like action by increasing peripheral glucose consumption, or it may enhance the activity of beta cells as occured due to glibenclamide, resulting in an increased insulin release and decreased blood glucose level [24].

During the second phase of experiment, diabetes was induced by the intraperitoneal injection of alloxan monohydrate. During this study neither glibenclamide nor extract has brought the serum glucose concentrations of alloxaninduced diabetic rabbits to normal range; the reason may be short duration of treatment. However, both the glibenclamide and extract caused significant reduction in serum glucose concentration as compared to diabetic control group $(P<0.05)$. The results of this research reflected the beneficial effects of plant extract on the glucose level of diabetic rabbits. The reduction in glucose level in extract-treated group may be due to the insulin-like effects of the extract, as insulin increases glucose uptake by the cells [25]. Reduction in glucose level of diabetic extract-treated group may also be due to the renewal of $\beta$ cells following extract administration. The renewal of $\beta$ cells in diabetes has been studied in several animal models. It has been suggested that regeneration of islet $\beta$ cells after the use of drug may be the primary cause of the recovery of alloxan-induced diabetic animals [26].

During the present study the serum levels of cholesterol, triglyceride and LDL were significantly elevated in diabetic animals. The abnormally high concentration of serum lipids in diabetes is mainly due to increase in the mobilization of free fatty acids from the peripheral fat depots [27]. According to the Framingham Heart study, dyslipidaemia which can range from hypercholesterolemia to hyperlipoproteinemia is one of the many modifiable risk factors for coronary artery diseases, stroke, and peripheral vascular disease [28]. During the present study, the reduction in serum glucose level of extract-treated diabetic rabbits was accompanied by marked reduction in the serum levels of cholesterol, triglyceride and LDL. This indicates the hypolipidemic effect of the Pentanema vestitum extract in diabetic rabbits. Markku (1995) [29] reported that glycemic control is the major determinant of total and VLDL triglyceride concentration. During the present study the glibenclamide also caused significant reduction in cholesterol, triglyceride and LDL. Improved glycaemia control following sulphonylurea therapy has also been shown to decrease VDL and total triglyceride levels [30].

In the present research, the plant extract and glibenclamide caused significant increase in serum HDL level. High density lipoproteins (HDLs) are very important as they possess antiatherosclerotic and anti-inflammatory properties [31]. Direct evidence for a protective effect of HDLs in atherosclerosis has come from transgenic mice in which high levels of expression of apoprotein A-1 (apoA-1) increased the concentration of HDL and protected mice against dietinduced atherosclerosis [32]. Epidemiological evidence suggests that increased level of low density lipoprotein (LDL) and low concentration of high density lipoprotein are associated with atherosclerosis [33]. The extract may cause increase in HDL level by inducing ApoA-1 production. Lahoz et al. (2003) suggested that increase in HDL levels after treatment may be due to the induction of ApoA-1 production [34].

The diabetic rabbits showed elevated levels of serum GPT, ALP and bilirubin. The levels of these parameters have been reported to be increased in alloxan-induced diabetic animals [35]. During the present study, there occurred 
reduction in the level of SGPT, ALP and bilirubin in the extract-treated rabbits. The reduction in these liver function parameters shows the hepatoprotective function of the plant extract. The observed hepatoprotective effects of plants are attributed to the presence of flavonoids, ascorbic acid, carotenoid, and phenolic compounds. These compounds are known to be antioxidant and free radical scavengers that lead to hepatoprotection $[15,36-39]$.

Serum creatinine level of diabetic rabbit was also elevated. Diabetic hyperglycemia leads to elevated levels of serum creatinine, urine total protein and urine albumin which are considered as significant markers of renal dysfunction [40]. During the present study the significant decrease in the serum creatinine level of extract-treated diabetic rabbits show the beneficial effects of the plant extract on the kidney function of diabetic rabbits. There are several reports on the nephroprotective properties of medicinal plants. Their nephroprotective function is mediated via antioxidant and/or free radical scavenging activities as they possess high concentration of flavonoids and alkaloids [41].

\section{Conclusion}

From the finding of the present research, it was concluded that the $70 \%$ methanol extract of Pentanema vestitum whole plant has beneficial effects on serum levels of glucose, lipid profile and also on liver and kidney function markers of diabetic rabbit models. No documented reports are available about the therapeutic values of this plant. The present research exposes this hidden medicinal plant to the communities interested in medicinal plants and herbal medication.

\section{Future Research}

Further research is needed on activity oriented fractionation, qualitative and quantitative screening of phytocomponents, and the nature and mechanism of action of hypoglycemic, hypolipidemic, hepatoprotective, and nephroprotective agents, found in Pentanema vestitum whole plant extracts. This plant may be a cheap source of therapeutic agents for pharmaceutical industry.

\section{References}

[1] D. B. Marks, A. D. Marks, and C. M. Smith, Basic Biochemistry: A Clinical Approach, Lippincott Williams \& Wilkins, Baltimore, Md, USA, 1996.

[2] S. Rajasekaran, K. Ravi, K. Sivagnanam, and S. Subramanian, "Beneficial effects of Aloe vera leaf gel extract on lipid profile status in rats with streptozotocin diabetes," Clinical and Experimental Pharmacology and Physiology, vol. 33, no. 3, pp. 232-237, 2006.

[3] A. S. Shera, F. Jawad, and A. Maqsood, "Prevalence of diabetes in Pakistan," Diabetes Research and Clinical Practice, vol. 76, no. 2, pp. 219-222, 2007.

[4] International Diabetes Federation, "Prevalence estimates of diabetes mellitus (DM)," MENA. IDF Diabetes Atlas, I.D.F., 3-9-2010, 2010.

[5] S. Arumugam, S. Kavimani, B. Kadalmani, A. B. A. Ahmed, M. A. Akbarsha, and M. V. Rao, "Antidiabetic activity of leaf and callus extracts of Aegle marmelos in rabbit," ScienceAsia, vol. 34, no. 3, pp. 317-321, 2008.

[6] WHO, "Diabetes Management and Control, A Call for Action," WHO-EM/DIA/3/E/G, 1993.

[7] V. S. Reddy, R. K. Sahay, S. K. Bhadada, J. K. Agrawal, and N. K. Agrawal, "Newer oral anti diabetic agents," Journal, Indian Academy of Clinical Medicine, vol. 1, pp. 245-251, 2000.

[8] M. S. Arayne, N. Sultana, A. Z. Mirza, M. H. Zuberi, and F. A. Siddiqui, "In vitro hypoglycemic activity of methanolic extract of some indigenous plants," Pakistan Journal of Pharmaceutical Sciences, vol. 20, no. 4, pp. 268-273, 2007.

[9] M. Ahmad, R. Qureshi, M. Arshad, M. A. Khan, and M. Zafar, "Traditional herbal remedies used for the treatment of diabetes from district attock (Pakistan)," Pakistan Journal of Botany, vol. 41, no. 6, pp. 2777-2782, 2009.

[10] M. Qaiser and R. Abid, Flora of Pakistan: Asteraceae (II) Inuleae, Plucheeae and Gnaaphalieae, vol. 210, Missouri Botanical Garden, St. Louis, Mo, USA, 2003.

[11] D. A. Bhagwat, G. K. Suresh, and S. A. Rahul, "Anti-diabetic activity of leaf extract Tridax procumbens," International Journal of Green Pharmacy, vol. 2, no. 2, pp. 126-128, 2008.

[12] H. Pareek, S. Sharma, B. S. Khajja, K. Jain, and G. C. Jain, "Evaluation of hypoglycemic and anti-hyperglycemic potential of Tridax procumbens (Linn.)," BMC Complementary and Alternative Medicine, vol. 9, article 48, 2009.

[13] P. W. Sherman and J. Billing, "Darwinian gastronomy: why we use spices: spices taste good because they are good for us," BioScience, vol. 49, no. 6, pp. 453-463, 1999.

[14] S. B. Sridhar, U. D. Sheetal, M. R. S. M. Pai, and M. S. Shastri, "Preclinical evaluation of the antidiabetic effect of Eugenia jambolana seed powder in streptozotocin-diabetic rats," Brazilian Journal of Medical and Biological Research, vol. 38, no. 3, pp. 463-468, 2005.

[15] M. J. Ahn and J. Kim, "Identification and quantification of steroidal saponins in Polygonatum species by HPLC/ESI/MS," Archives of Pharmacal Research, vol. 28, no. 5, pp. 592-597, 2005.

[16] T. Zhou, D. Luo, X. Li, and Y. Luo, "Hypoglycemic and hypolipidemic effects of flavonoids from lotus (Nelumbo nuficera Gaertn) leaf in diabetic mice," Journal of Medicinal Plant Research, vol. 3, no. 4, pp. 290-293, 2009.

[17] J. B. Harborne, Phytochemical Methods, Chapman and Hall, London, UK, 1973.

[18] D. O. Edem, "Hypoglycemic effects of ethanolic extracts of alligator pear seed (persea americana mill) in rats," European Journal of Scientific Research, vol. 33, no. 4, pp. 669-678, 2009.

[19] F. M. Matschinsky, "A lesson in metabolic regulation inspired by the glucokinase glucose sensor paradigm," Diabetes, vol. 45, no. 2, pp. 223-241, 1996.

[20] P. Maechler, S. Carobbio, and B. Rubi, "In beta-cells, mitochondria integrate and generate metabolic signals controlling insulin secretion," International Journal of Biochemistry \& Cell Biology, vol. 38, no. 5-6, pp. 696-709, 2006.

[21] B. Corkey, "Metabolic regulation of insulin secretion," in Pancreatic Beta Cell in Health and Disease, S. Seino, Ed., pp. 53-74, Springer, Tokyo, Japan, 2008.

[22] L. E. Fridlyand, N. Tamarina, and L. H. Philipson, "Modeling of $\mathrm{Ca}^{2+}$ flux in pancreatic $\beta$-cells: role of the plasma membrane and intracellular stores," American Journal of Physiology, vol. 285, no. 1, pp. E138-E154, 2003.

[23] F. M. Ashcroft, D. E. Harrison, and S. J. H. Ashcroft, "Glucose induces closure of single potassium channels in isolated rat pancreatic $\beta$-cells," Nature, vol. 312, no. 5993, pp. 446-448, 1984. 
[24] J. K. Andrew, Diabetes, Churchill Levingstone, New York, NY, USA, 2000.

[25] M. Latha, L. Pari, S. Sitasawad, and R. Bhonde, "Insulinsecretagogue activity and cytoprotective role of the traditional antidiabetic plant Scoparia dulcis (Sweet Broomweed)," Life Sciences, vol. 75, no. 16, pp. 2003-2014, 2004.

[26] K. C. Gorray, D. Baskin, J. Brodsky, and W. Y. Fujimoto, "Responses of pancreatic B cells to alloxan and streptozotocin in the guinea pig," Pancreas, vol. 1, no. 2, pp. 130-138, 1986.

[27] K. N. Bopanna, J. Kannan, S. Gadgil, R. Balaraman, and S. P. Rathod, "Antidiabetic and antihyperlipaemic effects of neem seed kernel powder on alloxan diabetic rabbits," Indian Journal of Pharmacology, vol. 29, no. 3, pp. 162-167, 1997.

[28] P. H. Chong and B. S. Bachenheimer, "Current, new and future treatments in dyslipidaemia and atherosclerosis," Drugs, vol. 60, no. 1, pp. 55-93, 2000.

[29] L. Markku, "Epidemiology of diabetic dyslipidemia," Diabetes Reviews, vol. 3, no. 3, pp. 408-422, 1995.

[30] R. K. Huupponen, J. S. Viikari, and H. Saarimaa, “Correlation of serum lipids with diabetes control in sulfonylurea-treated diabetic patients," Diabetes Care, vol. 7, no. 6, pp. 575-578, 1984.

[31] A. Wu, C. J. Hinds, and C. Thiemermann, "High-density lipoproteins in sepsis and septic shock: metabolism, actions, and therapeutic applications," Shock, vol. 21, no. 3, pp. 210-221, 2004.

[32] E. M. Rubin, R. M. Krauss, E. A. Spangler, J. G. Verstuyft, and S. M. Clift, "Inhibition of early atherogenesis in transgenic mice by human apolipoprotein A1," Nature, vol. 353, no. 6341, pp. 265-267, 1991.

[33] T. Gordon, W. P. Castelli, M. C. Hjortland, W. B. Kannel, and T. R. Dawber, "High density lipoprotein as a protective factor against coronary heart disease. The Framingham study," American Journal of Medicine, vol. 62, no. 5, pp. 707-714, 1977.

[34] C. Lahoz, R. Peña, J. M. Mostaza et al., "Apo A-I promoter polymorphism influences basal HDL-cholesterol and its response to pravastatin therapy," Atherosclerosis, vol. 168, no. 2, pp. 289-295, 2003.

[35] J. Gonzalez and J. Fevery, "Spontaneously diabetic biobreeding rats and impairment of bile acid-independent bile flow and increased biliary bilirubin, calcium and lipid secretion," Hepatology, vol. 16, no. 2, pp. 426-432, 1992.

[36] M. Fauré, E. Lissi, R. Torres, and L. A. Videla, "Antioxidant activities of lignans and flavonoids," Phytochemistry, vol. 29, no. 12, pp. 3773-3775, 1990.

[37] S. S. Handa, A. Sharma, and K. K. Chakraborti, "Natural products and plants as liver protecting drugs," Fitoterapia, vol. 57, no. 5, pp. 307-351, 1986.

[38] A. W. Harman, "The effectiveness of antioxidants in reducing paracetamol-induced damage subsequent to paracetamol activation," Research Communications in Chemical Pathology and Pharmacology, vol. 49, no. 2, pp. 215-228, 1985.

[39] Y. Oshima, Y. Kawakami, Y. Kiso, H. Hikino, L. L. Yang, and Yenky, "Antihepatotoxic principles of Aeginatia indica herbs," Shoyakugaku Zasshi, vol. 38, pp. 198-200, 1984.

[40] R. G. Bretzel, "Prevention and slowing down the progression of the diabetic nephropathy through antihypertensive therapy," Journal of Diabetes and Its Complications, vol. 11, no. 2, pp. 112-122, 1997.

[41] N. J. Miller and C. A. Rice-Evans, "The relative contributions of ascorbic acid and phenolic antioxidants to the total antioxidant activity of orange and apple fruit juices and blackcurrant drink," Food Chemistry, vol. 60, no. 3, pp. 331-337, 1997. 

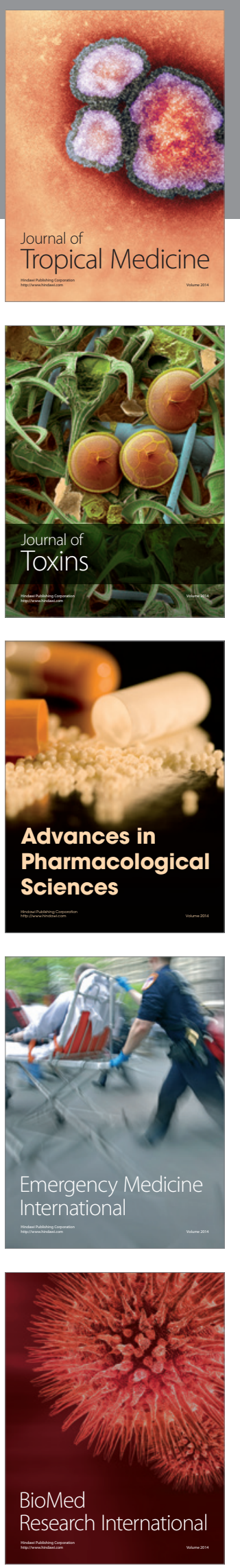
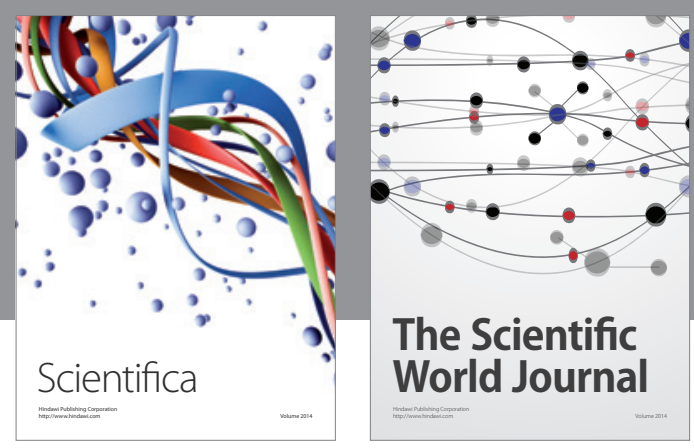

The Scientific World Journal
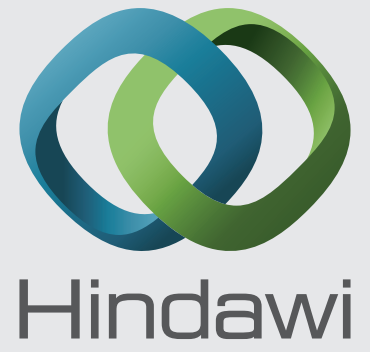

Submit your manuscripts at

http://www.hindawi.com
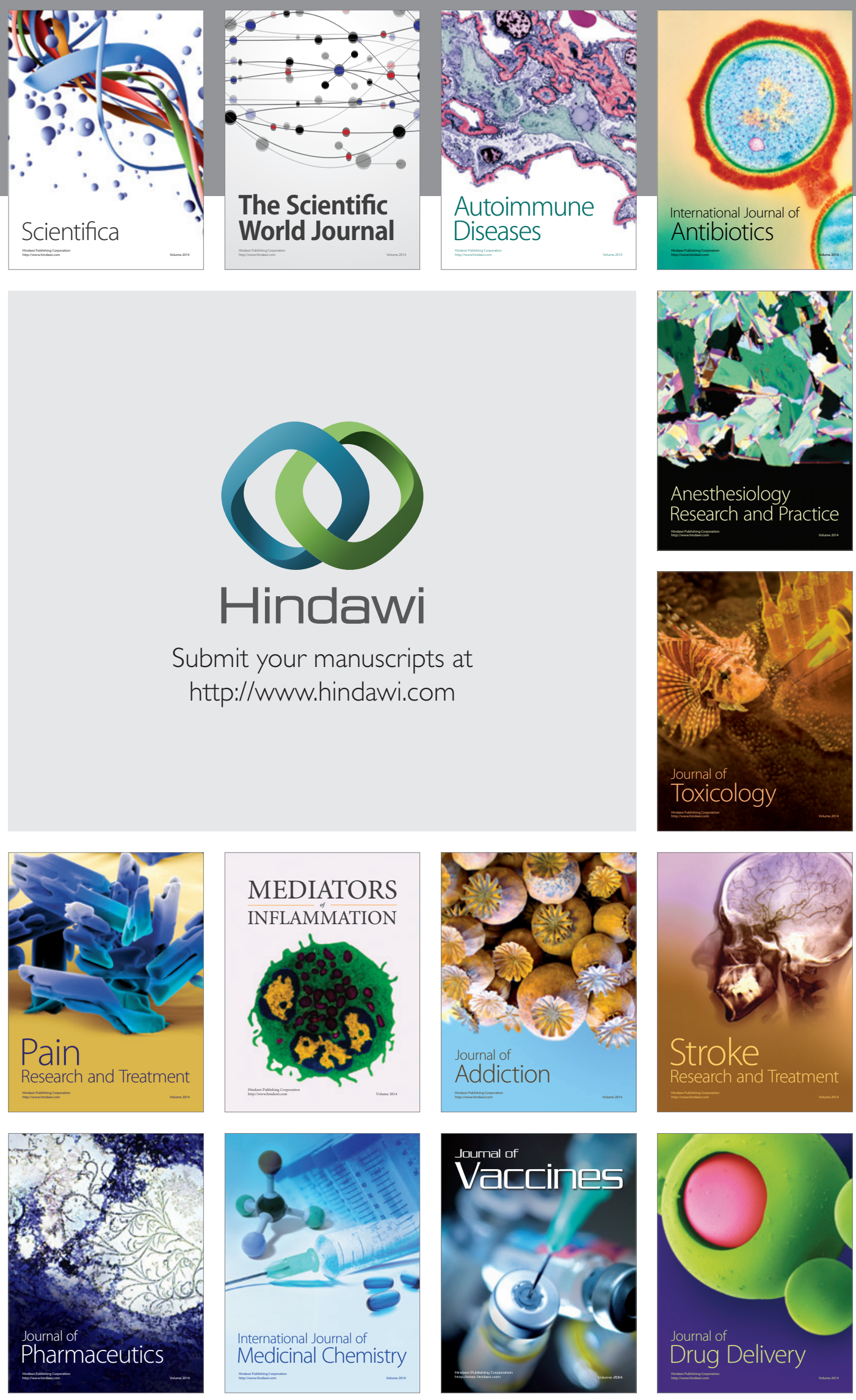